\title{
Esterification of high free fatty acids in supercritical methanol using sulfated angel wing shells as catalyst
}

\begin{abstract}
In this research, shells of Cyrtopleura costata, commonly known as angel wing, were used to prepare sulfated calcined angel wing shell (CAWS) catalysts by a simple, low-cost method. The produced CAWS-SO $\mathrm{S}_{4}$ catalyst was characterized by using X-ray diffraction (XRD), Fourier transmission infrared spectroscopy (FTIR), temperature programmed desorption of $\mathrm{CO}_{2}$ and $\mathrm{NH}_{3}\left(\mathrm{CO}_{2}\right.$-TPD and $\mathrm{NH}_{3}$-TPD), BET surface area analysis and variable pressure scanning electron microscopy (VP-SEM). The esterification of palm fatty acid distillate (PFAD) by supercritical methanol was successfully performed to obtain the high fatty acid methyl esters (FAME) with yield of $98 \%$ at the optimum methanol/PFAD molar ratio of 6/1, 2 wt. $\%$ catalyst loading, $290{ }^{\circ} \mathrm{C}$ in $15 \mathrm{~min}$. The catalyst could also be reused up to seven cycles with a FAME yield higher than $80 \%$ in the last cycle. The characterization of spent catalyst has been performed by using XRD, FTIR, TPD-NH 3 and SEM.
\end{abstract}

Keyword: Sulfated calcium oxide; Waste shell; Esterification; Biodiesel; Supercritical 